\title{
Design and Research of a New Type of Horizontal Wave Flow Power Generator
}

\author{
Wanchao Ren ${ }^{1, \mathrm{a}}$, ShiMing Wang, \\ ${ }^{1}$ Room105, College of Engineering, Shanghai Ocean \\ University, No.999, Hu Cheng Huan Road, Lingang new \\ city, Shanghai, P.R.China
}

\begin{abstract}
This paper introduces a new type of horizontal wave flow power generatoreveloped by Shanghai Ocean University. Expound from its working principle, capturing mechanism and its key part of acquire energy. And it's provided a profitable thinking for farther experiment.
\end{abstract}

Keywords-ocean energy; capturing mechanism; horizontal wave

\section{INTRODUCTION}

In the mutual promotion of resourse, economy, environment and territory consciousness. National governments attach unprecedented importance to the technology of development and utilization“ Blue Ocean” which is accounted for $71 \%$ of the earth's surface. Ocean power generation is the main way to exploit ocean currently[1].At present, there are exist some kind of equipment, such asoscillating buoy,oscillating water column and wave overtopping etc, but these type have drawback of structural complexity, the costs of electricity are valuableness, generating efficiency is very low[2-4].Thus we designed one turbine type of generating set that integrate wave energy and tidal current energy. The design has advantages of simple construction, low cost, power generation efficiency, and remote-controlled, so it have innovative value.

\section{WORKING PRINCIPLE Of System AND The MACHINE STRUCTURE}

\section{A. Working principle}

The power generation system of new type of marine integrated turbine includes horizontal type straight blade Turbine device, mechanical transmission, remote real-time monitoring system and safety support system. The overall design shown in figure 1.The capture device shown in figure 2.This system floating on the sea surface by the safety protection system and fixed by the anchor. Horizontal turbine is drove by the integrated power of tidal range and wave to complete the transformation from the ocean energy to the rotating mechanical energy, and then it will transmit to the side generator through the growth mechanism, so to realize electrical energy conversion. At the same time, the remote monitoring system placed on top of a device and above the water will take back the power generation data real-time. When the system is in abnormal work(severe weather such as hurricanes),the up-and-down system of the safety protection will open the protection

\author{
${ }^{2}$ Room301, College of Engineering, Shanghai Ocean \\ University, No.999, Hu Cheng Huan Road, Lingang new \\ city, Shanghai, P.R.China \\ a370323378@qq.com,,smwang@shou.edu.cn
}

function and then dive voluntarily to avoid the influence of the bad weather.

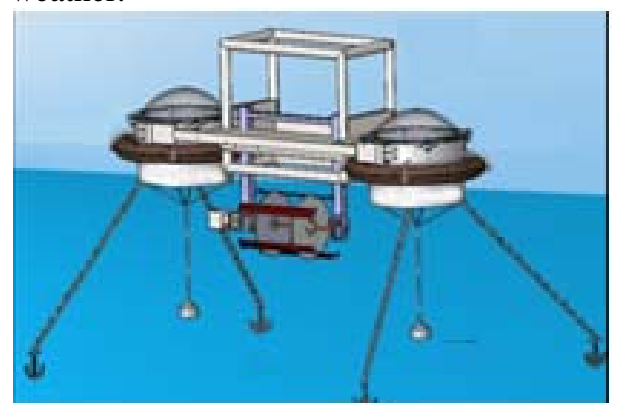

Figure 1. Generating system overall design
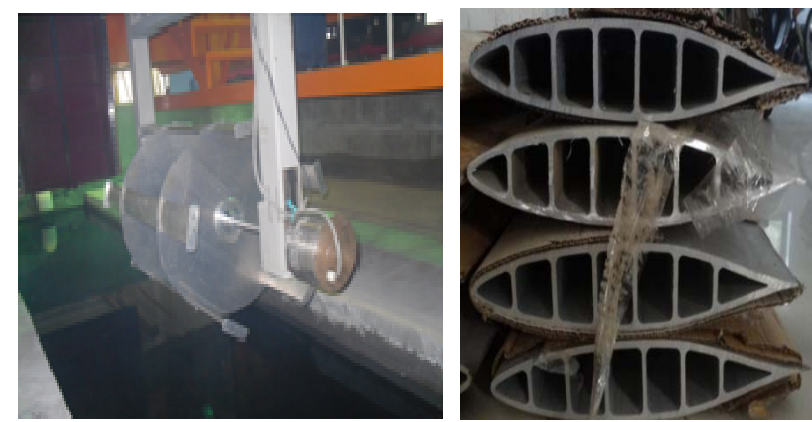

Figure 2. Horizontal turbine capturing mehanism' s outline drawing

\section{B. Capturing mechanism}

Horizontal turbine capturing mechanism as the mainly mechanism that absorb wave energy. The structural is similar to the vertical axis Tidal Turbine, mainly includes the airfoil blade, spokes, shaft, bearing and shaft sleeve. The turbine structure as shown in figure 3.Leaf blade uniformly distributed in the circular disc, the circular disc and turbine main shaft are fixed, and through the fixed bearing embed into the inner side of the machine frame sealing speed mechanism, realized the demand of the changes from turbine's low speed high torque to the generator's high speed low torque. Starting from the design philosophy [5] of wind turbine, preliminary we use the 5 blade NACA63-018 symmetrical airfoil structure, combine with the optimal blade design theory of variable motion of waves and currents to design the blade's chord length, elongation etc [6].After determine the blade geometry, referencing the design of vertical axis Tidal Turbine and combining with the blade lift drag coefficient curve. According to BEM theory, work out the parameter 
distribution of moment and thrust of the whole turbine.

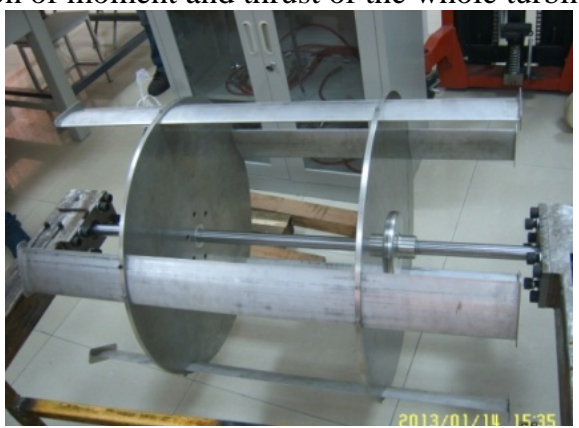

Figure 3. Prototype mode of stationary blade turbine

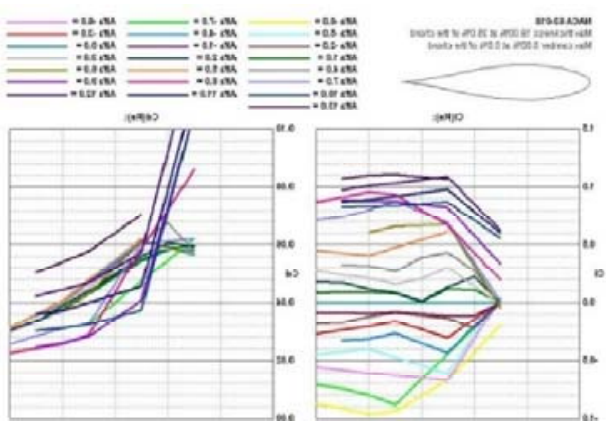

Figure 4. Blade lift and drag Coefficient curve

\section{Ups and downs of safety protection system}

This ups and downs of safety protection system mainly depends on the volume change principle and PLC control technology to realize the rise and fall of the device. A single ups and downs device appearance and internal actuators as shown in figure 5.This system mainly completes the outer seal structure, the buoy body, positioning moored, external airbags, and its internal actuators. As shown in figure 5(b), the valve 1,2,3,4 respectively in the internal and external airbags and connected with air pump. On the principle of distribution of bridge, when the system is sinking at work, the valve 1, 3 will open, the valve 2, 4 will close, and then the air compressor will work. The gas will move along with the red path from external airbags to internal airbags. Till the gas transmission is completed, the valve 13 will close, and the system will complete the sinking movement. When the device floating, the system will use another working mechanism contrary to the sinking process. In this two process, air pump will complete two sets of action to save space of equipment and reduce the energy consumption. The key principle of design is

$\sum_{i=1}^{n} M_{i} g=\rho V_{\text {out }} g$

Where:

$\sum_{i=1}^{n} M_{i}$ is t quality $\left(k_{g}\right)$ of generator parts

$\rho$ issea-water density $\left(1025 \mathrm{~kg} / \mathrm{m}^{3}\right)$

$V_{\text {out }}$ is the volume of the gasbags change $\left(\mathrm{m}^{3}\right)$

$\mathrm{g}$ isacceleration of gravity $(9.8 \mathrm{~m} / \mathrm{s} 2)$

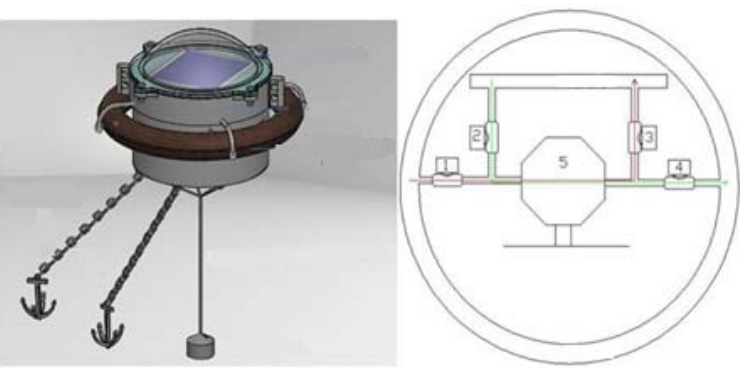

$\begin{array}{ll}\text { (a) The outline of the device } & \text { (b) Internal structure of gasbags }\end{array}$ Figure 5 . The structure diagram of safety protection system

\section{Flume experiment analysis}

Our project team was carried out flume experiment at National Center of Ocean Standards and Metrology. Figure 6isinstallation drawing of the flume experiment. Horizontal turbine fixed in the bottom of tank test platform.

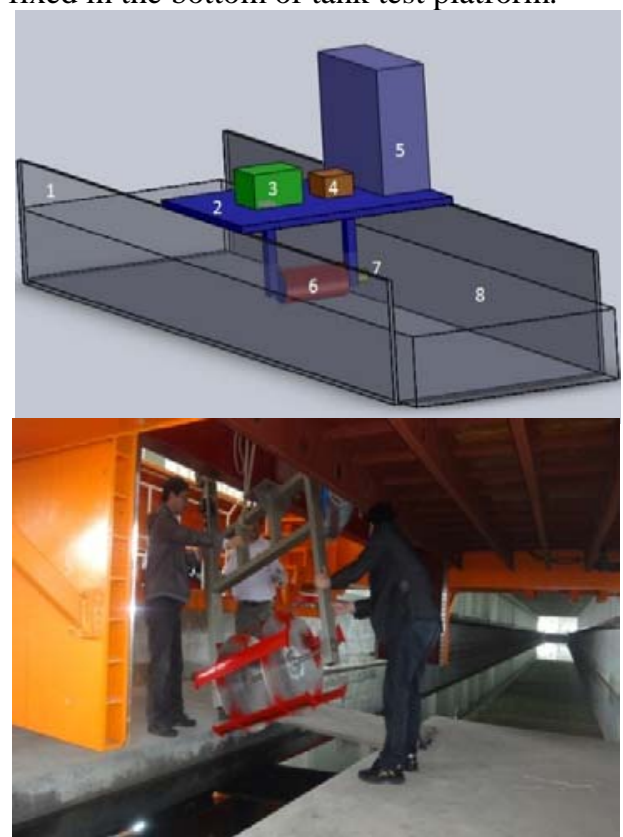

1-flume 2- mobile test platform 3- hardware devices of remote monitor 4-motor test system 5-speed control room 6-turbine 7-generator 8-horizontal plane

Figure 6. Installation drawing of the flume experiment

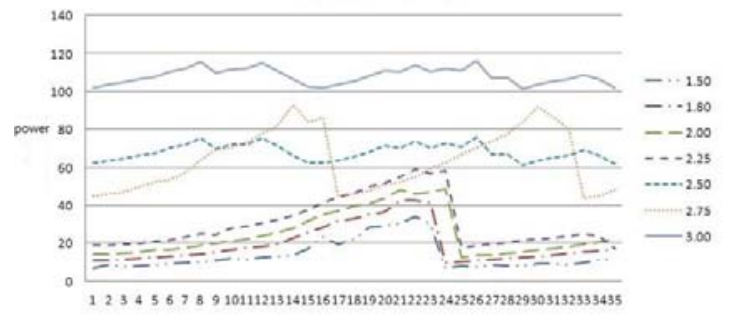

Figure 7. Output power diagram

So based on the electronic load with constant load, and recorded the whole system power under different flow 
conditions can map system load power output as shown in figure 7.By the experiment, we know that horizontal turbine began to dirve high torque motor running in $1.5 \mathrm{~m} / \mathrm{s}$ flow conditions and can provide $20 \mathrm{~W}$ power system. With the increase of working conditions, the highest power is about $112 \mathrm{~W}$ when the velocity at $3 \mathrm{~m} / \mathrm{s}$ flow condition. In addition, chosen rotational armature three-phase synchronous generator rated power is $950 \mathrm{~W}$,rated speed is $750 \mathrm{r} / \mathrm{min}$, by the early stage of the motor performance test, when the motor speed to $753 \mathrm{r} / \mathrm{min}$, the motor output power is 205.7W.The actual efficiency of generator is $21.6 \%$.According to the efficiency, combined with the system average output power in all kinds of flow conditions, we can calculate horizontal hydraulic actual input system power P1.Compared with the theory of power of the Matlab in $2 \mathrm{~m} / \mathrm{s}$ flow conditions, we can know that the reduced value of flume experimentis less than the theoretical value, this is mainly due to the energy loss in the water tank test and motor matching relations.

\section{CONCLUSION}

This paper introduces a new type of horizontal wave flow power generator developed by Shanghai Ocean University. It expound many aspects, such as working principle, security prevention system. Flume experiments confirmed that horizontal wave flow power generator with high capacity characteristics. Horizontal turbine began to drive high torque motor running in $1.5 \mathrm{~m} / \mathrm{s}$ flow conditions and can provide $20 \mathrm{~W}$ power system. With the increase of working conditions, the highest power is about $112 \mathrm{~W}$ when the velocity at $3 \mathrm{~m} / \mathrm{s}$ flow condition. The flume experiment of horizontal turbine provide a reliable reference for later device system's optimization and experience.

\section{CORRESPONDING AUTHOR}

Name: Ren wanchao

Email: 370323378@qq.com

Mobile phone: 13262975586

\section{REFERENCES}

[1] Johanes Falnes: A review of wave-energy ectraction. Marine structure. 20(2007), p.185-201.

[2] Miguel Esteban, David Leary: Current developments and future prospects of offshore wind and ocean energy. Applied Energy. 90(2012), p.128-136.

[3] Mohamed M H: Performance investigation of H-rotor Darrieus turbine with new airfoil shapes. Energy. 47(2012), p.522-530.

[4] Antheaume S, Maître T, Achard J L: Hydraulic Darrieus turbines efficiency for free fluid flow conditions versus power farms conditions. Renewable Energy. 33(2008), p.2186-2198.

[5] Miguel Esteban. David Leary: Current developments and future prospects of offshore wind and ocean energy. Applied Energy. 90(2012), p. 128-136.

[6] Johanes Falnes. A review of wave-energy ectraction. Marine structure. 20(2007),p.185-201. 